Nordin, A., Moberg, R., Tønsberg, T., Vitikainen, O., Åsa Dalsätt, Myrdal, M., Snitting, D., \& Ekman, S.A Manual to Santesson's Checklist of Fennoscandian Lichen-forming and Lichenicolous Fungi. Ver. April 29, 2011. Retrieved on March 25, 2019 from:http://130.238.83.220/santesson/Santesson_manual.pdf.

Otalora, M., Jorgensen, P.M., \& Wedin, M. A revised generic classification of the jelly lichens, Collemataceae.In: Fungal Diversity, 2014 (64), pp. 275-293.

S.M. Alverdiyeva Baku, Azerbaijan

\title{
DIVERSITY OF FOLIOSE LICHENSPECIES IN AZERBAIJAN
}

Abstract. This article consolidates lichenological data on foliose lichens of Azerbaijan and addresses their species diversity. It was determined that the studied lichens belong to classes Eurotiomycetes, Lecanoromycetes and Lichenomycetes of the phylum Ascomycota. They are represented by 166 species, including 8 orders: Caliciales, Candelariales, Lecanorales, Peltigerales, Teloschistales, Umbilicariales, Verrucariales, Lichinales; 15 families: Candelariaceae, Collemataceae, Lecanoraceae, Lobariaceae, Nephromataceae, Pannariaceae, Parmeliaceae, Peltigeraceae, Peltylaceae, Physciaceae, Placynthiaceae, Stereocaulaceae, Teloschistaceae, Umbilicariaceae, Verrucariaceae; and 51 genera. Such species as Anaptychia elbursiana, Enchylium ligerinum, Phaeophyscia hirsuta, Parmelia fraudans, Physconia perisidiosa, Punctelia rudecta,Tuckermannopsis chlorophylla, and Umbilicaria proboscidea are new to the lichen flora of the studied region. The article provides information on the location in the studied region, the substrate and the ecological group for each species. It was found that the species diversity of foliose lichens is is mainly formed by five polymorphic families, such as Parmeliaceae, Physciaceae, Collemataceae, Peltigeraceae, and Umbilicariaceae, thatcomprise 132 species (79.5\% of the total number of species). Among genera, only five of themhave significant species diversity: Peltigera (17 species), Physcia (15), Umbilicaria (13), Collema (9) and Parmelia (5). As for the humidity factor, five groups were distinguished: mesophytes (132 species), xerophytes (17), xeromesophytes (9), hygromezophytes (6), mesoxerophytes(2). As for the substrate, foliose lichens were devided into five ecological and substrate groups: epiphytes (53 species), epilites (48), epigeids (22), epibriophytes (18), eurysubstrate linchens (25).

Key words: Azerbaijan; species diversity; foliose; lichen.

About the author: Sevda Mukhtar gyzy Alverdiyeva, Candidate of Biological Sciences, Leading Researcher.

Place of employment: Institute of Botany, AzerbaijanNational Academy of Sciences.

Алвердиева С.М. Видовое разнообразие листоватых лишайников Азербайджана // Вестник Нижневартовского государственного университета. 2019. № 2. С. 20-31.

Alverdiyeva S.M. Diversity of foliose lichenspecies in Azerbaijan // Bulletin of Nizhnevartovsk State University. 2019. No. 2. P. $20-31$

УДК 581.95

3.А. Самойленко, Б.Ф. Свириденко

2. Сургут, Россия

\section{НОВЫЕ НАХОДКИ ПОПУЛЯЦИЙ ПИОНА УКЛОНЯЮЩЕГОСЯ В СУРГУТСКОМ РАЙОНЕ ХАНТЫ-МАНСИЙСКОГО АВТОНОМНОГО ОКРУГА - ЮГРЫ}

\footnotetext{
Аннотация. В статье описано два новых местонахождения популяций Paeonia anomala L. - пиона уклоняющегося (марьина корня), редкого вида, включенного в Красную Книгу Ханты-Мансийского автономного округа - Югры, обнаруженных в Сургутском районе. Выявлены фитоценотические, топографические и экологические условия произрастания популяций, а также их количественные параметры: численность, плотность, возрастная структура. Первая популяция характеризуется довольно высокими показателями плотности и численности в сравнении с другими популяциями, обследованными ранее, а также значительно большим участием в составе популяции генеративных особей. Другие биометрические параметры (среднее число побегов на одно растение, средшее количество генеративных и вегетативных побегов, высота и число листьев на генеративных и вегетативных побегах) практически не уступают популяциям, развитым в оптимальных для них экологических условиях лесостепи. Вторая популяция уступает по многим показателям (численность, плотность, высота и число листьев генеративных и вегетативных побегов) первой, большинство особей находятся в вегетативном состоянии, среднее количество побегов на одну особь также невелико. Полученные сведения расширяют наши представления о численности и структуре популяций этого редкого и исчезающего вида в регионе.

Ключевые слова: Paeonia anomala; новые местонахождения; Красная книга; Ханты-Мансийский автономный округ - Югра.
} 
Сведения об авторах: Зоя Анатольевна Самойленко ${ }^{1}$, кандидат биологических наук, доцент кафедры биологии и биотехнологии; Борис Федорович Свириденко ${ }^{2}$, доктор биологических наук.

Место работы: ${ }^{1,2}$ Сургутский государственный университет.

Контактная информация: ${ }^{1,2} 628400$, г. Сургут, ул. Энергетиков, д. 22, каб. 633, тел.: 8(3462) 76-31-54, 1e-mail: zoyasl@yandex.ru; ${ }^{2}$ bosviri@mail.ru.

Планомерная работа по выявлению новых местонахождений популяций редких видов растений, внесенных в Красную Книгу ХантыМансийского автономного округа $(2003,2013)$, ведется сотрудниками кафедры биологии и биотехнологии Сургутского государственного университета уже более 15 лет. Результаты этой работы нашли свое место в новом издании региональной Красной Книги, опубликованной в 2013 г., а также отражены в ряде публикаций. Данная статья продолжает серию публикаций (Самойленко и др. 2009; Свириденко и др. 2010; Свириденко и др. 2011) о новых находках редкого вида (3 категория) Paeonia anomala $\mathrm{L}$. - пиона уклоняющегося в XМАО - Югре, а именно на территории Сургутского района, где в июне 2018 г. были обнаружены 2 новые популяции этого вида.

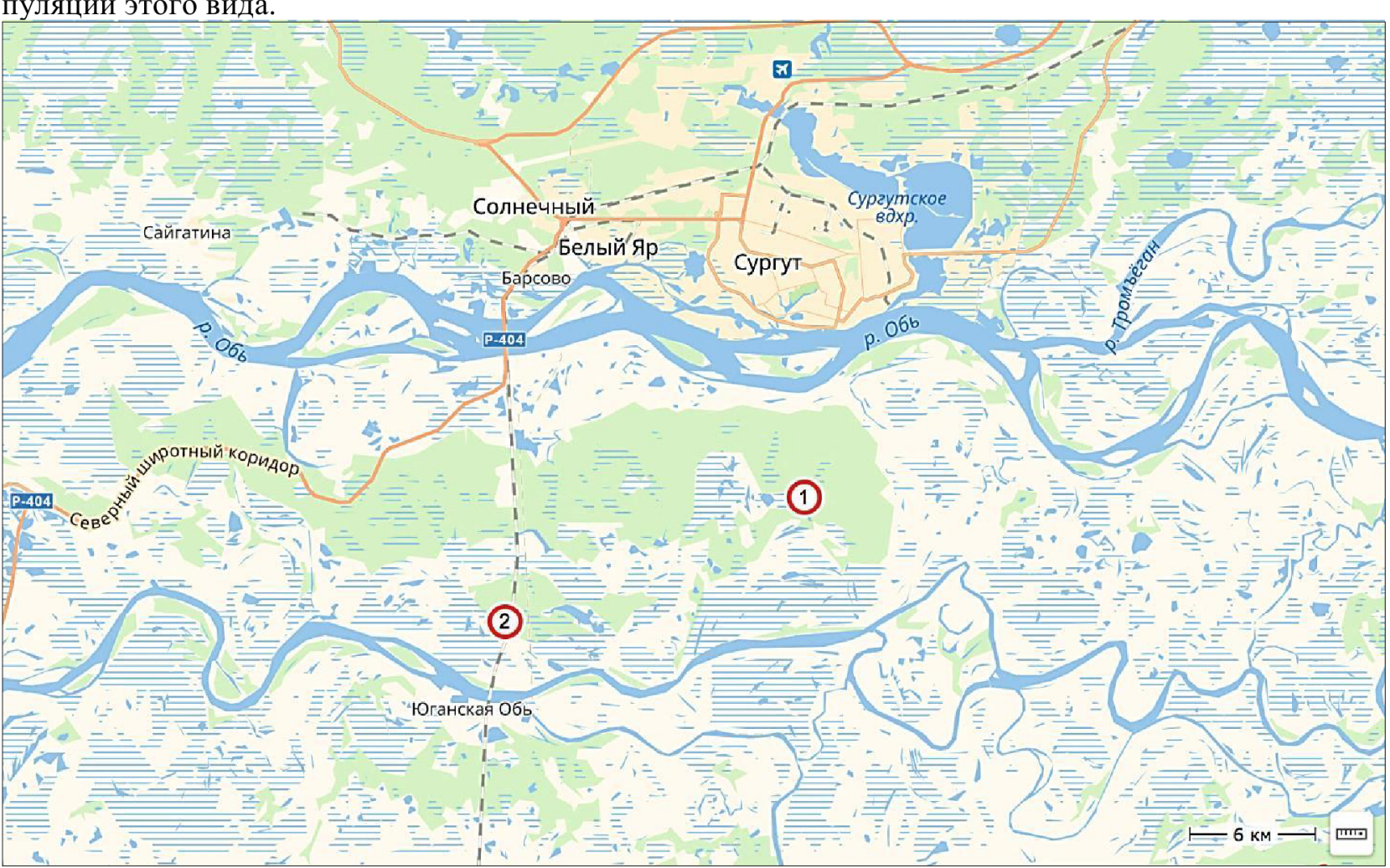

Рис. 1. Новые местонахождения популяций Paeonia anomala в Сургутском районе

"Цифрами в кружках обозначены номера популяций

Исходное сообщество представляло собой пихтово-кедровый разнотравный лес, пострадавший от пожара предположительно более 10 лет назад. В настоящее время гарь зарастает осиной (Populus tremula L.) и березой (Betula pendula Roth.) высотой $1,5-4,0$ м, образую-
Первая популяция отмечена на зарастающем после пожара склоне четвертой надпойменной террасы в долине р. Обь, имеющем юго-восточную экспозицию (рис. 1), с величиной уклона около $35-40^{\circ}$. Географические координаты популяции: 61 $09^{\prime} 16^{\prime \prime}$ с.ш., $73^{\circ} 25^{\prime} 45^{\prime \prime}$ в.д. Площадь выгоревшего участка около 0,6 км$^{2}$, плошадь данной популяции Paeonia anomala составляет 0,004 км² при длине занимаемого участка 200 м и ширине около 20 м. Выгоревший участок на севере граничит с коренным пихтово-кедровым кустарничковомелкотравным лесом. Южная часть склона примыкает к одной из проток р. Обь и полосе пойменной луговой растительности, тянущейся вдоль ее русла. 
(ПП) 35\%, Rosa majalis Herrm. (10\%), Viburnum opulus L. (1\%), Rubus sachalinensis H. Lev. (5\%). На повышенных участках (бывших приствольных повышениях) с невысоким проективным покрытием отмечены кустарнички Vaccinium vitis-idaea L. и Vaccinium myrtillus L.

Общее проективное покрытие травяного яруса составляет 75\%. Ярус разделяется на 2 подъяруса. Первый подъярус - высокотравье высотой до 1,5 м, имеет ОПП около $60 \%$. В его составе доминируют такие виды, как Milium effusum L. (30\%), Paeonia anomala (15-30\%), Aconitum septentrionale Koelle. (15\%), Cacalia hastata L. (7\%), Chamerion angustifolium (L.) Holub. (8\%). С небольшим проективным покрытием отмечены: Hierochloe odorata (L.) Beauv. (3\%), Polemonium caeruleum L. $(<1 \%)$. Во втором подъярусе значительное покрытие (7-18\%) имеют Stellaria bungeana Fenzl (18\%),

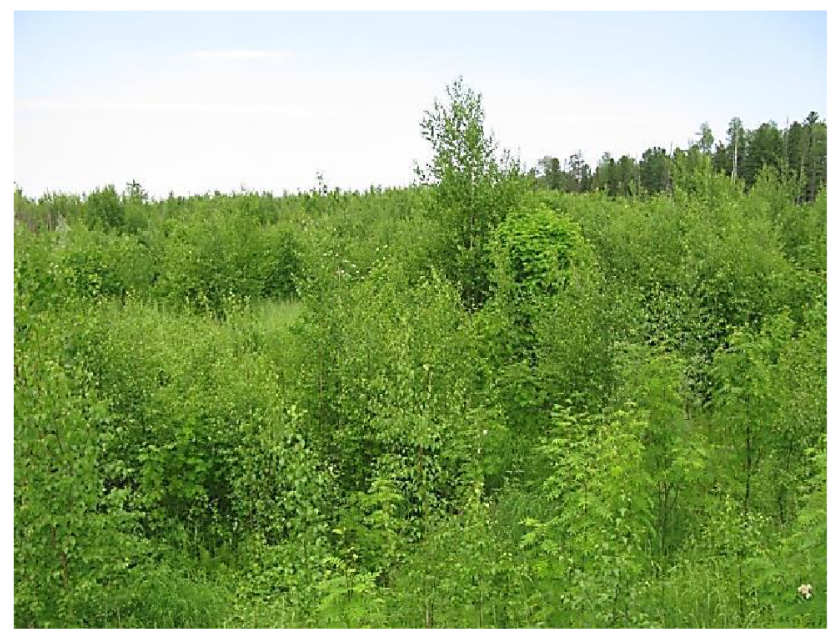

$a$
Rubus saxatilis L. (8\%), Equisetum pratense Ehrh. (10\%), Rubus arcicus L. (5\%), Equisetum sylvaticum L. C менышим проективным покрытием представлены Atragene sibirica L. (5\%), Maianthemum bifolium (L.) F.W. Schmidt (5\%), Actaea erythrocarpa (Fisch.) Freyn (3\%), Galium boreale L. (3\%), Gymnocarpium dryopteris (L.) Newm. Присутствуют также Vicia cracca L. (2\%), Luzulapilosa (L.) Willd. (2\%), Paris quadrifolia L. (1\%), Anemonodium dichotomum (L.) Holub (1\%), Lactuca sibirica (L.) Benth. ex Maxim. (1\%). B нижней части склона на границе с пойменным лугом отмечены Lamium album L., Filipendula ulmaria (L.) Maxim. и кустарник Swida alba (L.) Opiz. На приствольных повышениях, оставшихся от поврежденного древостоя, встречается мох Polytrichum juniperinum Hedw. Флористический состав фитоценоза с участием Раеоnia anomala представлен 34 видами.

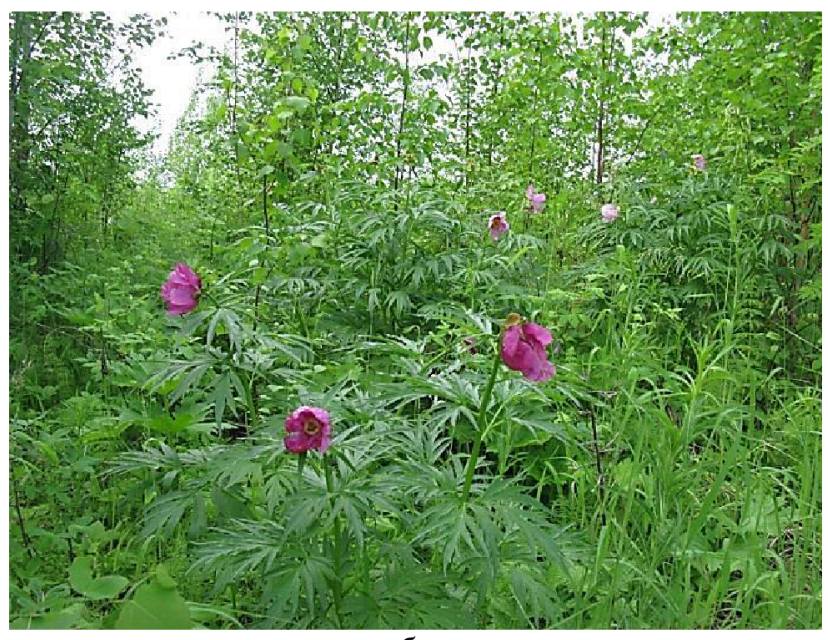

6

Рис. 2. Фитоценоз с участием Paeonia anomala в долине р. Обь: a - общий вид, б - генеративные особи Paeonia anomala в данном фитоценозе

Численность данной популяции пиона насчитывает 350 особей. Плотность популяции составляет 0,093 особи/м². Распределение особей пиона достаточно равномерное. Если сравнивать с популяциями, описанными нами ранее в Нефтеюганском и Сургутском районах $(\mathrm{Ca}-$ мойленко и др. 2009; Свириденко и др. 2010; Свириденко и др. 2011), данная популяция отличается более высокими показателями плотности и численности, а также значительно большим участием в составе генеративных особей (72,6\% от числа особей). Известно, что жизненность Paeonia anomala зависит от интенсивности освещения, вид предпочитает открытые и полуоткрытые пространства, опушки в пихтово-еловых и смешанных лесах, поляны и лесные луга (Барыкина, Чубатова 2007). Вероятно, пожар оказал положительное воздейст- вие на развитие данной популяции в связи с увеличением освещенности участка из-за устранения древесного яруса. В то же время пожары в начале вегетации вида могут привести и к уничтожению его популяции. Отмечено, в частности, что примыкающие к изученной популяции участки старой гари подверглись новым пожарам весной 2018 г, в результате чего молодой подрост берез и осин пострадал и, соответственно, сократилась популяция пиона, которая ранее занимала более значительную площадь на данном склоне.

Одним из параметров благоприятного развития популяции пиона является среднее число побегов на одно растение. Этот показа-

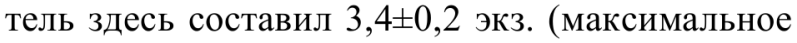
число побегов достигало 11 экз. на одно растение), из них среднее количество генеративных 
побегов составляло 2,9 $\pm 0,2$ экз. (максимум 11 экз.), вегетативных побегов $-0,4 \pm 0,1$ экз. (максимум 4 экз.).

Высота генеративных побегов Paeonia anomala составляла $86,5 \pm 0,9$ см $(\mathrm{n}=223)$, среднее количество листьев на генеративный побег достигало 8,03 $\pm 0,09$ эк3. $(\mathrm{n}=223)$. Вегетативные побеги имели высоту $52,1 \pm 2,7$ см $(\mathrm{n}=32)$, среднее количество листьев на вегетативный

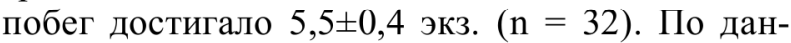
ным показателям обнаруженная популяция не уступает популяциям, развивающимся в оптимальных условиях в лесостепной полосе Западной Сибири (Семенова 2007). Установлен полночленный одновершинный тип возрастного спектра популяции. Наибольшая численность приходится на генеративные особи $(72,6 \%)$, доля остальных возрастных групп невелика (рис. 4). Данная популяция была обследована в фазе цветения, поэтому семенная продуктивность не изучена.

Вторая популяция найдена на высоком правобережном мезосклоне долины р. Юганская Обь (рис. 1), имеющем южную экспозицию с уклоном 35-40․ Географические коор-

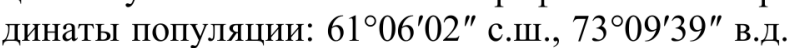
Рельеф склона неоднороден, он прерывается неглубокими логами, обращенными к руслу реки. Популяция сформировалась в березовокедровом кустарниково-разнотравном лесу (рис. 3). В древесном ярусе преобладает сосна сибирская Pinus sibirica DuTour с небольшим участием Betula pendula (формула леса 8К2Б). Сомкнутость крон 0,7. Высота древостоя 25 м, диаметр стволов сосны сибирской в среднем 25-30 см, березы повислой - 16-18 см. Подрост высотой до 3-4 м, средней густоты, выражен преимущественно по днищам логов, образован видами Pinus sibirica и Abies sibirica Ledeb.

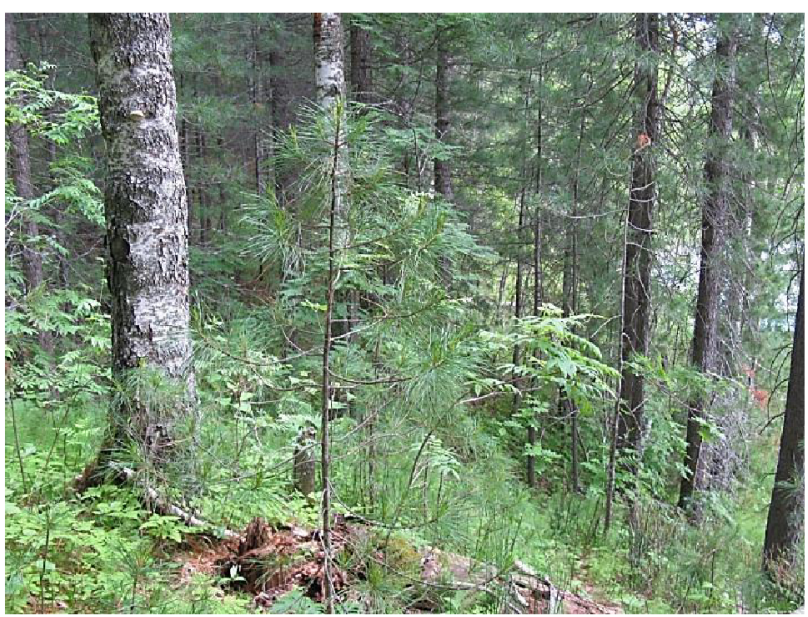

$a$
Кустарниковый ярус характеризуется общим проективным покрытием около 10-15\%, высотой от 1 до 5 м и образован Sorbus sibirica (10\%), Rosa majalis и Rosa acicularis Lindl.

Кустарничковый ярус развит слабо (5$7 \%$ и состоит из видов Vaccinium vitis-idaea (1\%), Vaccinium myrtillus (3\%), Linnaea borealis L. (3\%), Atragene sibirica (высота 1-2 м, до 5\%).

Травяной ярус развит хорошо (ОПП около 80-85\%, высота 25 см), в составе его встречено 27 видов. В травостое доминируют (2030\%) Rubus saxatilis и Aconitum septentrionale. В качестве содоминантов (10-15\%) участвуют Equisetum sylvaticum, Equisetum hyemale L., Maianthemum bifolium, Gymnocarpium dryopteris, Paeonia anomala. Достаточно обильны (ПП 5-7\%) Equisetum pratense, Dryopteriscarthusiana (Vill.) H.P. Fuchs., Cacalia hastata, Carex macroura Meinsh, Oxali sacetosella L., Galium boreale, Stellaria bungeana. Из южнотаежных и неморальных видов растений с небольшим покрытием рассеянно представлены Milium effusum, Geranium sylvaticum L., Heracleum sibiricum L., Actaea erythrocarpa, Paris quadrifolia I.,, Diplazium sibiricum (Turcz. exG.Kunze) Kurata.

Единично произрастают Trientalis europaea L., Luzula pilosa, Orthilia secunda (L.) House, Pyrola minor L., Lycopodium annotinum L.

Из редких и охраняемых растений, внесенных в региональную Красную Книгу (2013), помимо Paeonia anomala отмечен очень редкий для региона вид Allium victorialis L. (incl.A.microdyction Prokh.), имеющий ПП 67\%, а местами 50-70\%.

Моховой ярус практически отсутствует и представлен Pleurozium schreberi (Willd. exBrid.) Mitt. (до 1\%).

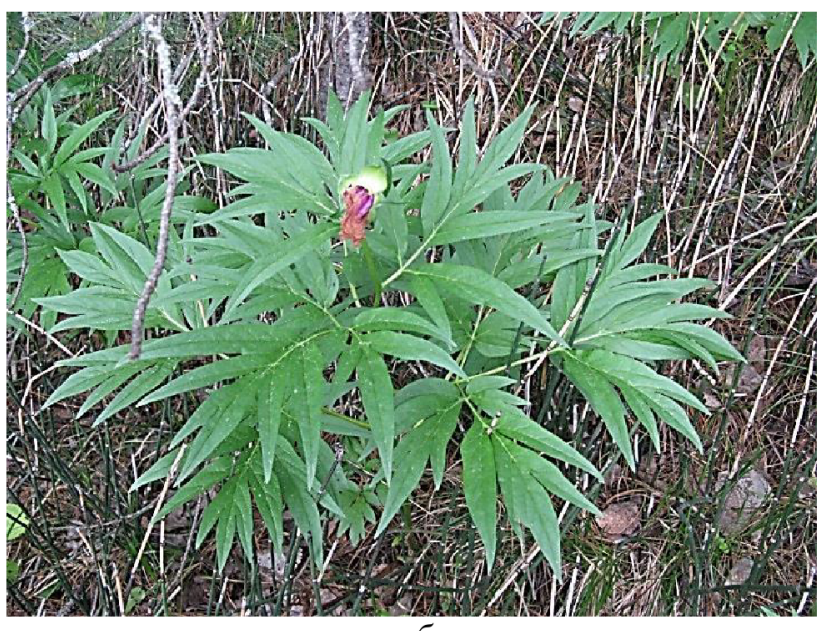

б

Рис. 3. Фитоценоз с участием Paeonia anomala в долине р Юганская Обь: a - общий вид, б - генеративная особь Paeonia anomala в данном фитоценозе 
Площадь этой популяции не превышает 0,002 км $^{2}$. Численность составляет 224 особи, причем генеративные растения редки $(6,7 \%$ численности). Большинство особей находилось в вегетативном состоянии, из них сенильные растения составили $8,9 \%$ (рис. 4б). Среднее количество вегетативных побегов у одного растения равно 0,95 $\pm 0,3$ экз., среднее количество

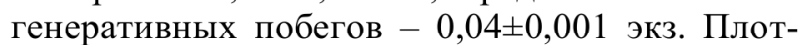
ность популяции не превышает 0,052 особей $/ \mathrm{M}^{2}$. Высота вегетативных побегов равна $21,0 \pm 0,9$ см ( $\mathrm{n}=113)$, среднее количество листьев на вегетативный побег составило $3,0 \pm 0,1$ экз. $(\mathrm{n}=113)$. Высота генеративных по-

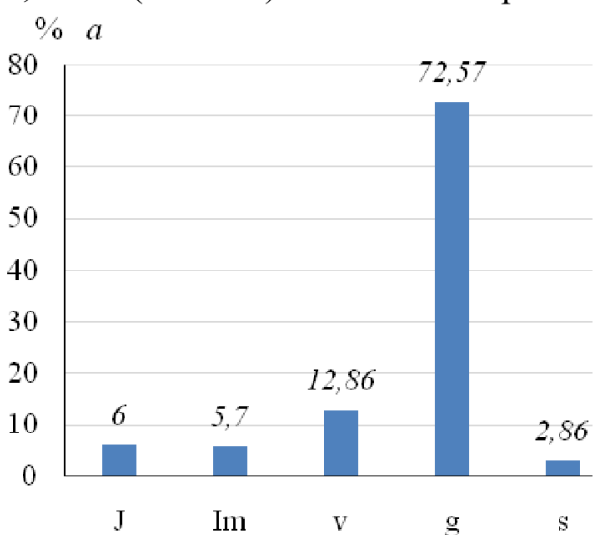

бегов Paeonia anomala составляла $54,2 \pm 4,0$ cм $(\mathrm{n}=5)$, среднее количество листьев на генеративный побег достигало $6,6 \pm 0,4$ экз. $(\mathrm{n}=5)$. По приведенным популяционным параметрам вторая популяция значительно уступает первой, что, вероятно, связано с большей степенью затенения и использованием вида в декоративных и лекарственных целях.

Возрастной спектр второй исследованной популяции Paeonia anomala имеет полночленный одновершинный тип, но при малой численности генеративных особей. Данная популяция также была обследована в фазе цветения, поэтому семенная продуктивность не изучена.

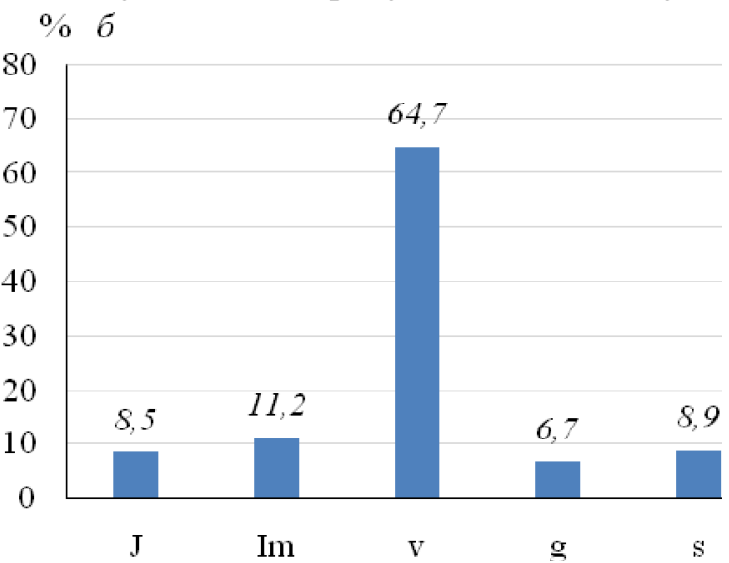

Рис. 4. Возрастные спектры популяций Paeonia anomala в долине р. Объ (а) и в долине р. Юганская Обь (б) По оси абсцисс - возрастные состояния особей: $j$-ювенильное, іт - имматурное, v-виргинильное, $g$ - генеративное, $s$-сенильное; по оси ординат - доля особей, \%

Популяции Paeoniaanomala в Сургутском районе связаны с высокими террасами Оби и крутыми склоновыми участками южной и юговосточной экспозиции. Ранее высказанное предположение (Свириденко и др. 2011) о перспективности надпойменных террас долины р. Обь для поиска новых популяций редких видов растений еще раз подтвердилось.
Для сохранения популяций пиона в регионе необходимо контролировать его численность, включать соответствующие экосистемы в число особо охраняемых природных территорий. Также не менее важной является работа с населением по экологическому просвещению и воспитанию с акцентированием внимания на общесоциальной задаче сохранения редких видов биоты региона.

\section{ЛИТЕРАТУРА}

Барыкина Р. П., Чубатова Н. В. 2007. Онтогенез пиона уклоняющегося (Paеопia anomala L.) // Онтогенетический атлас. Т. V. Йошкар-Ола: Изд-во МарГУ, 191-197.

Красная книга Ханты-Мансийского автономного округа - Югры. Животные, растения, грибы. 2003. Екатеринбург: Изд. дом «Парус».

Красная книга Ханты-Мансийского автономного округа - Югры. Животные, растения, грибы. 2013. Екатеринбург: Баско.

Самойленко 3. А., Свириденко Б. Ф., Шепелева Л. Ф. 2009. Новые данные о популяциях пиона уклоняющегося Paeonia anomala (Paeoniaceae) в Ханты-Мансийском автономном округе // Экологический вестник Югории VI:4, 28-34.

Свириденко Б. Ф., Ефремов А. Н., Самойленко 3. А. 2010. Состояние популяций пиона уклоняющегося Paeonia anomala (Paeoniaceae) на северной границе распространения в Западной Сибири // Вестник Томского государственного университета. Биология 3(11), 38-46.

Свириденко Б. Ф., Шепелева Л. Ф., Самойленко 3. А. 2011. Состояние популяций пиона Paеoniaanomala в Сургутском и Нефтеюганском районах Ханты-Мансийского автономного округа - Югры // Шепелева Л.Ф. (отв. ред.). Сб. паучных трудов биологического факультета. Вып. 8. Сургут: ИЦ СурГУ, 312. 
Семенова Г. П. 2007. Редкие и исчезающие виды флоры Сибири: биология, охрана. Новосибирск: Академическое изд-во «Гео».

\section{REFERENCES}

Barykina, R.P., \& Chubatova, N.V. Ontogenez piona uklonyuschegosya (PaeoniaanomalaL.) [Ontogenesis of anomalous peony (Paeonia anomala L.)]. In:Ontogeneticheskiy atlas. T. V [Ontogenetic atlas. Vol. 5]. Yoshkar-Ola: Izdatelstvo MarGU, 2007, pp. 191-197. (In Russian).

Krasnaya kniga Khanty-Mansiyskogo avtonomnogo okruga - Yugry.Zhivotnyye, rasteniya, griby [The Red Book of Khanty-Mansiysk Autonomous Area -Yugra. Animals, Plants, Mushrooms].Yekaterinburg: Parus, 2003. (In Russian).

Krasnaya kniga Khanty-Mansiyskogo avtonomnogo okruga - Yugry. Zhivotnyye, rasteniya, griby [The Red Book of Khanty-Mansiysk Autonomous Area - Yugra. Animals, Plants, Mushrooms]. Yekaterinburg: Basko, 2013. (In Russian).

Samoylenko, Z.A., Sviridenko, B.F., \&Shepeleva, L.F. Novyye dannyye o populyatsiyakh piona uklonyayushchegosya Paeonia anomala (Paeoniaceae) v Khanty-Mansiyskom avtonomnom okruge [New data on anomalous peony Paeonia anomala (Paeoniaceae) populations in Khanty-Mansi Autonomous Okrug]. In: Ekologicheskiy vestnik Yugorii, 2009 (VI), issue 4, pp. 28-34. (In Russian).

Sviridenko, B.F., Yefremov, A.N., \& Samoylenko, Z.A. Sostoyaniye populyatsiy piona uklonyayushchegosya Paeonia anomala (Paeoniaceae) na severnoy granitse rasprostraneniya v Zapadnoy Sibiri [The state of anomalous peony Paeonia anomala (Paeoniaceae) populations found on the northern border of distribution area in Western Siberia]. In: Vestnik Tomskogo gosudarstvennogo universitreta. Biologiya, 2010 (3), issue 11, pp. 38-46. (In Russian).

Sviridenko, B.F., Shepeleva, L.F., \& Samoylenko, Z.A. Sostoyaniye populyatsiy piona Paeonia anomala v Surgutskom i Nefteyuganskom rayonakh Khanty-Mansiyskogo avtonomnogo okruga - Yugry [The status of Paeonia anomala populations in the Surgutsky and Nefteyugansky districts of Khanty-Mansi Autonomous Okrug -Yugra]. In: Sbornik nauchnykh trudov biologicheskogo fakulteta. Vyp. 8 [Collection of scientific works of the Biology Faculty. Vol. 8]. Ed. by L.F. Shepeleva. Surgut: IC SurGU, 2011, pp. 3-12. (In Russian).

Semenova, G.P. Redkiye i ischezayushchiye vidy flory Sibiri: biologiya, okhrana [Rare and Endangered Species of Siberian Flora: Biology, Protection]. Novosibirsk: Geo, 2007. (In Russian).

\section{Z.A. Samoylenko, B.F. Sviridenko Surgut, Russia}

\section{NEW PAEONIA ANOMALA POPULATIONS FOUND IN SURGUTSKY DISTRICT OF KHANTY-MANSIYSK AUTONOMOUS AREA - YUGRA}

Abstract. The article describes two new localities of Paeonia anomala L., a rare species listedin the Red Data Book of the Khanty-Mansiysk Autonomous Area - Yugra, that were discovered in Surgutsky District. Phytocenotic, topographic and ecologic growth conditions were studied, and quantitative data on abundance, density and age composition of the populations were collected. The first population is characterized by rather high density and abundance in comparison with other populations examined earlier;the number of generative shoots is also significantly larger. Other biometric parameters (average number of shoots per plant, average number of generative and vegetative shoots, height and number of leaves on generative and vegetative shoots) are similar to those of populations that developed in the optimal ecological conditions of the forest steppe.The second population is inferior to the first one in many respects (abundance, density, height and quantity of leavesof generative and vegetative shoots); most of the plants are in the vegetative state; and the average number of shoots per plant are also small. The obtained data expand our understanding of the size and structure of the populations of this rare and endangered species in the region.

Keywords:Paeonia anomala;new locality; Red Book; Khanty-Mansiysk Autonomous Area-Yugra.

About the authors: Zoya Anatolyevna Samoylenko, Candidate of Biological Sciences, Associate Professor of the Department of Biology and Biotechnology; Boris Fedorovich Sviridenko, Doctor of Biological Sciences.

Place of employment: Surgut State University.

Самойленко 3.А., Свириденко Б.Ф. Новые находки популяций пиона уклоняющегося в Сургутском районе Ханты-Мансийского автономного округа - Югры // Вестник Нижневартовского государственного университета. 2019. № 2. C. 31-36.

Samoylenko Z.A., Sviridenko B.F. New paeonia anomala populations found in Surgutsky district of KhantyMansiysk autonomous area - Yugra // Bulletin of Nizhnevartovsk State University. 2019. No. 2. P. 31-36. 